\title{
От окулистических "летучих" отрядов до офтальмологических бригад по обследованию населения
}

Организация выездных офтальмологических приемов на территории страны неразрывно связана с историей деятельности Попечительства императрицы Марии Александровны о слепых, которое положило начало выездам в 1893 г. и доказало несомненную пользу их для населения. Тема работы актуальна и на сегодняшний день ввиду продолжения этой работы посредством организации выездных офтальмологических приемов и оказания офтальмохирургической помощи населению из отдаленных городских и сельских поселений. Актуальность выездов рождает интерес к изучению истории выездной деятельности. Особое внимание к истории данной работы проявляют сами офртальмологи. К примеру, директор Санкт-Петербургского фрилиала ФГАУ "НМИЦ "МНТК "Микрохирургия глаза" им. акад. С.Н. Федорова" Минздрава России Э.В. Бойко с соавторами в своей работе оценивают масштабность проделанной офтальмологическими отрядами работы под руководством профрессора Л.Г. Беллярминова [6, с. 100]. Ценность и важность работы выездных отрядов заключается в том, что они охватывали труднодоступные регионы страны. Командировки в отдаленные регионы сопровождались проблемами организационного характера: отсутствие устойчивой транспортной связи становилось препятствием для выполнения запланированного объема работы по обследованию населения. Т.А. Князькина, на примере работы офтальмологического отряда в Камчатской области, указывает на эти факторы [11, с. 83]. Значимость выездной детельности обозначается в работе А.И. Акманова с соавтором посредством указания фрактов развертывания амбулаторных и стационарных отделений офртальмологического профиля после осуществления командировок "летучих" отрядов в регион [1, с. 53].

Целью данной работы является анализ деятельности и сравнительная характеристика фрункционирования окулистических "летучих" отрядов на территории Уфимской губернии, трахоматозных отрядов - в Башкирии и современных офртальмологических отрядов в Башкортостане.

Научная работа преследует задачи исследовать общественную и практическую значимость деятельности попечительства императрицы Марии Александровны о слепых в плане оказания выездной офтальмологической помощи в регионе; показать преемственность между частной благотворительной организацией и государственными учреждениями здравоохранения, указать их различия и проблемы на пути становления.

Частное благотворительное общество Попечительство императрицы Марии Александровны о слепых возникло 13 февраля 1881 г. в результате реорганизации Главного попечительства для пособия нуждающимся семействам воинов, убитых и раненых в Русско-турецкую войну. Причиной тому стало большое количество слепых и слабовидящих людей, которые потеряли зрение вне военных действий: из обследованных 444 больных только 5\% потеряли зрение во время военных действий $[18$, с. 21]. Первопричина увеличения количества населения с заболеваниями органа зрения кроилась в распространении трахомы, которая была завезена на территорию России с войсками, вернувшимися после оккупации Франции в 1817-1818 гг. Отсутствие внимания со стороны

(C) Бикбов М. М., Галилова Ю. Ш., 2021

БИкБОВ Мухаррам Мухтарамович, д-р мед. наук, профессор, директор Уфимского научно-исследовательского института глазных болезней Академии наук Республики Башкортостан (2. Уgбa). E-mail: eye@anrb.ru

ГАЛИМОВА Юлия Шагимурдановна, аспирант кафедры истории России, историографии и источниковедения Башкирского государственного университета (2. У $б a)$. E-mail: yula347@gmail. com 
государства к этой проблеме и, соответственно, недоступность получения своевременного лечения вкупе с социально-экономической отсталостью страны и низкой культурой населения привели к тому, что к концу XIX в. - к началу $\mathrm{XX}$ в. трахома стала лидирующим заболеванием глаза, приводящим к слепоте, в том числе необратимой. Согласно данным профр. С.С. Головина, трахома стала причиной слепоты у 21,4\% обследованного населения, у 19,2\% - глаукома, у $13,5 \%$ - болезни роговицы др. [2, с. 12-13].

Таким образом, Попечительство о слепых возглавило осуществление поддержки слепых и слабовидящих людей, преследуя две цели: оказание офртальмологической помощи населению и услуг по попечению инвалидов по зрению [22, с. 174]. Перед организацией стояла задача обеспечить офтальмологической помощью 189872 инвалидов по зрению, выявленных Центральным Статистическим комитетом в 1886 г., что составляло 20 слепых на 10000 населения [19, с. 5].

Одним из направлений деятельности Попечительства о слепых, и одним из самых действенных, стала организация с 1893 г. так называемых "летучих отрядов", направляемых в летнее время в сельскую местность для оказания специализированной медицинской помощи. В 1893 г. было направлено 7 отрядов, в 1894 г. -21 , в 1895 г. - 24, в 1896 г. - 21, в 1897 г. - 33, 1898 г. - 36 отрядов [15, с. 21]. За 20 лет работы было направлено 535 глазных отрядов, которыми была оказана консультативная помощь 4 млн. больным с заболеваниями глаз и произведено 900 тыс. оперативных вмешательств [6, с. 95].

В среднем каждый отряд в период своей работы, который длился от одного до двух месяцев, принимал около двух тысяч пациентов [13, с. 107]. Кроме консультационной и хирургической помощи врачебный персонал отряда по возможности занимался подготовкой врачей и младшего медицинского персонала на местах с целью обучения их элементарным навыкам ухода за больными с заболеваниями органа зрения.

Согласно переписи населения империи в 1886 г., в Уфимской губернии было 35 слепых на 10 тыс. населения, в Казанской губернии - 45 человек, Симбирской - 37, Вятской - 36 [8, с. 20]. Организация работы глазных отрядов на территории Уфимской губернии осуществлялось Уфимским отделением Попечительства и уездными земскими управами. Первый глазной отряд в Уфримскую губернию прибыл в 1897 г. За период 1897-1913 гг. на территорию губернии было направлено 18 отрядов (РГИА. Ф. 764. Оп. 1. Д. 556, 564, $565)^{1}$.

Одними из первых во главе отрядов на территорию Уфимской губернии прибыли врачи Игирейт и Соловьев в 1897 г. Помощь отрядами оказывалась бесплатно. Об их приезде заранее сообщалось населению через объявления в периодической печати. В 1899 г. сроком на 2 месяца в г. Стерлитамак приезжал профессор кафредры офтальмологии Томского университета С.В. Лобанов [9, с. 130]. Отряд в составе доктора Яковлева, студента Казиева и местных врачей Брауде и Ладыгина работал с 28 мая по 24 июня 1899 г. За этот период прием прошли 3272 пациента, из которых 856 получили хирургическое лечение $[14$, c. 15]. Для стационарных больных были отведены две палаты в земской больнице, рассчитанные на 36 коек и три палаты вместимостью 13 коек в помещении приюта для неизлечимо больных. Из 3272 пациентов для 363 был выставлен диагноз "неизлечимая слепота". Причинами слепоты стали трахома, глаукома и болезни роговой оболочки. Приезд доктора С.В. Лобанова стимулировало Стерлитамакское земство развернуть в городе с 1900 г. глазную лечебницу на четыре койки $[23$, с. 1$]$.

В этом же году был осуществлен выезд отряда на территорию Белебеевского уезда $[\mathbf{1 4}$, с. 10]. Местом его дислокации было выбрано с. Семеново-Макарово. В составе отряда был врач Исупов и студент Шерман. Из-за отсутствия местной больницы для отряда и размещения пациентов были выделены избы местных жителей: 3 избы для оперированных больных, 2 избы на 20 человек для пациентов, нуждавшихся в наблюдении и 1 дом для врачебного персонала. Земство выделило 1000 руб. на приобретение лекарств и перевязочного материала, также по 5 коп. выдавалось пациентам на питание. В последующем отряд был переброшен в г. Белебей, где он проработал в течение 16 дней.

1 РГИА - Российский государственный исторический архив. 
Помощь отряду оказывали доктора Остроумов и Соколов. Последний впоследствии возглавил постоянный офтальмологический пункт при земской больнице [15, с. 80]. За 1 месяц и 22 дня работы отряд оказал помощь 1202 пациентам, при этом 510 больным была оказана хирургическая помощь [14, с. 10]. Из числа оперированных у 237 больных было проведено устранение заворота века после трахомы, что составило $46,5 \%$ оперативных вмешательств. Неизлечимо слепых было выявлено 85 человек, причинами чего являлись трахома, глаукома, оспа и болезни роговой оболочки. В стационаре помощь получили 58 человек.

Очередной отряд в г. Белебей приезжал в 1903 г. Отряд возглавил ученик профрессора Л.Г. Беллярминова и будущий профрессор глазной клиники Кубанского медицинского института С.В. Очаповский [9, с. 6]. В ходе работы врачом было принято 2003 пациента, оказана оперативная помощь 938 обратившимся [16, с. 62].

В 1901 г. на территорию Удимского уезда прибыл глазной отряд под началом доктора А.А. Бельского [3, с. 3]. "Летучий" отряд начал работу в д. Ардальоновка Уфимского уезда, где временная глазная лечебница стала фрункционировать в здании земской больницы [15, с. 5]. В помощь отряду были направлены земские врачи Виммерман, Филиппов и Тринитатов [15, с. 4]. Отряд работал с 3 по 31 мая 1901 г. и оказал первичную помощь 1597 больным. Далее "летучий" отряд приступил к работе в Уфе, где прием осуществлялся с 3 июня по 29 июня 1901 г. В составе отряда, кроме заведующего А.А. Бельского с помощником, был член Совета Уфимского отделения Попечительства врач С.П. Знаменский. Младший медицинский персонал состоял из четырех фрельдшеров. Под временную глазную лечебницу была выделена Чижевская больница на 25 коек $[15$, с. 5]. Из-за наплыва пациентов вместо 25 человек в больнице находилось 39 больных, которые размещались в коридорах больницы и даже на полу. Дополнительно была выделена квартира в здании Уфимского отделения Попечительства. Пациентам выдавался чай и хлеб. Больные преимущественно были из г. Уфы и близлежащих населенных пунктов, но 37 пациентов преодолели расстояние от 150 до 200 верст, а 66 человек - от 100 до 150 верст [15, 24-25]. Отряд в течение одного месяца работы проконсультировал 2285 пациентов, выполнил 524 операции в стационаре и 424 оперативных пособия, которые производились в амбулаторных условиях и не требовали госпитализации в стационар лечебного учреждения (НАРБ. Ф. И-311. Оп. 1. Ед. хр. 2, Л. 34) ${ }^{2}$. Хирургической помощью в стационаре Чижевской больницы смогли воспользоваться 82 человека, которые провели на лечении не менее 10 дней $[\mathbf{1 5}, \mathbf{c .}$ 5]. Больше всего за медицинской помощью обратилось больных с заболеванием трихиаз, который обычно возникал у пациентов с трахомой - 1297 человек, на втором месте по количеству заболеваний был катар соединительной оболочки, диагностированный у 1156 человек [15, с. 26-27]. Всего за время нахождения в У фимской губернии отряд принял 3482 пациента, выполнил 1057 операций и 830 оперативных пособий [3, с. 3.].

Глазные отряды выполняли важную миссию ввиду отсутствия какой-либо медицинской помощи в отдаленных губерниях Российской империи. Огромная территория государства и отсутствие путей сообщения приводило к тому, что выезды занимали очень много времени [1, с. 53]. К примеру, работа летучего отряда, направленного в Камчатскую волость длилась 7 месяцев, из которых только 73 дня врачебный персонал оказывал помощь [11, с. 83.]. К тому же в условиях выездной работы не было возможности оказать стационарную помощь пациентам при сложных диагнозах и ответственность за получение дальнейшего лечения и его успех перекладывался на самих больных, которые зачастую не понимали всю серьезность своего заболевания. Они либо не имели возможности обратиться в ближайшее лечебное учреждение, либо таковой медицинской организации вовсе не существовало, как, например, в той же Камчатской волости.

Таким образом, "летучие" отряды под началом Попечительства о слепых являлись практически первопроходцами в предоставлении офтальмологической помощи населению. Составляемые во время работы отряда отчеты помогали получить информацию, которая также указывала на необходимость

2 НАРБ - Национальный архив Республики Башкортостан 
организации постоянной офтальмологической службы на местах. Кроме того, приезды офртальмологических отрядов приучали население обращаться за медицинской помощью к квалифицированным специалистам [15, с. 80]. К сожалению, большая территория страны и отсутствие фринансов частного благотворительного общества с минимальными вливаниями от государства, нехватка квалифицированных кадров не позволяли охватить всё население, нуждавшееся в офтальмологической помощи. $K$ примеру, на 120 миллионов населения империи, как указывал профессор Л.Г. Беллярминов, было только 209 офртальмологов [9, с. 61]. Немаловажной проблемой была безграмотность населения с нежеланием обращаться к врачам и несоблюдение населением санитарно-эпидемиологических норм, усугубляющих ситуацию с распространением, в частности, трахомы.

В 1917 г. учреждения Попечительства императрицы Марии Александровны о слепых были ликвидированы, соответственно, работа глазных отрядов была прекращена. Послереволюционный период в стране характеризовался распространением эпидемиологических заболеваний, в том числе трахомы. И если к сопровождавшим трахому инфекционным заболеваниям таким, как холера, тиф, скарлатина, оспа, корь, со стороны государства было пристальное внимание ввиду масштабных смертельных исходов, то трахома, как поражающее зрение заболевание, находилась на периферии $[\mathbf{1 7}, \mathbf{c .} 99]$. С увеличением масштабов распространения трахомы государство пыталось предпринимать специальные меры для сдерживания заболевания. Так, для организации борьбы с трахомой развертывались противотрахоматозные учреждения: трахоматозные сестринские и фрельдшерские пункты, трахоматозные диспансеры, научно-исследовательские трахоматозные институты. Одновременно готовились кадры врачей, фрельдшеров, медицинских сестер. Но самое главное, была реанимирована работа глазных отрядов, которые направлялись в очаги заболевания и фринансировались государством. Возобновление этой деятельности произошло в стране в 1923 г., когда был сформирован первый глазной отряд. Затем Наркомат здравоохранения страны при участии Российского Общества Красного Креста и Наркоматов здравоохранения отдельных республик в 1924-1925 гг. организовал работу 30, в 1925-1926 гг. - 44, 1926-1927 гг. - 73 глазных отрядов [13, с. 108]. Первый глазной отряд на территории Башкирии также начал свою работу в 1923 г. под началом Башкирского наркомата здравоохранения.

Роль ведущего научного и клинического учреждения по борьбе с трахомой в республике была предоставлена Башкирскому научно-исследовательскому трахоматозному институту, который был открыт 31 декабря 1926 г. Для руководства Институтом и всей противотрахоматозной деятельностью в республике был приглашен профессор В.П. Одинцов - директор Глазной клиники Первого Московского медицинского института и уроженец Уфы.

Заболеваемость трахомой была достаточно высокой. К примеру, среди 12 тыс. пациентов, осмотренных в Калегинской волости Бирского кантона Башкирии, 90\% оказались зараженными трахомой [7, с. 2]. Кроме сбора статистических данных выездная работа давала возможность анализировать предпосылки распространения заболевания. Согласно анализу заболеваемости трахомой во время работы глазных отрядов в 1925-1934 гг. было выявлено, что у лиц чувашской национальности средний процент заболеваемости составил $70,5 \%$, у марийцев $-70 \%$, мордвы $-50 \%$, у татар и башкир $-25 \%$, русских $-1 \%$ [25, с. 13]. К тому же наиболее подверженными трахоме были жители степных районов Башкирии, нежели из горно-лесной местности. Грамотность также была значимым фактором в распространенности заболевания. Обследование населения Зилаирского кантона показало, что среди грамотных башкир процент заболеваемости составил $16 \%$ и соответственно $84 \%$ - у неграмотных башкир [21, с. 3]. К тому же женщины были подвержены трахоме больше мужчин, но самый большой процент заболеваемости был у детей, в том числе новорожденных.

В первое десятилетие - в 1925 - 1934 гг. сотрудниками Башкирского трахоматозного института было организовано 46 глазных отрядов, которыми было обследовано 147100 человек [20, с. 6]. Как указывал в своих воспоминаниях профрессор Р.Г. Кудояров, "... работавшие в бригадах проводили обследование и оказывали консервативную и хирургическую полощь. ... Лечение 
проводилось в больницах, трахолатозных пунктах, школах, клубах и специально организованных трахолатозных долах" [12, с. 158].

Для проведения выездной исследовательской работы привлекались медицинские бригады из столицы и других регионов страны. Так, в 1934 г. на территорию республики была направлена "Московская экспедиция по борьбе с трахомой", благодаря работе которой первичную офтальмологическую помощь получили более 14 тыс. человек [10, с. 107]. Сотрудники Башкирского трахоматозного института, в свою очередь, выезжали в соседние области, где оказывали помощь населению.

В годы Великой Отечественной войны выезды отрядов были прекращены, но в послевоенный период они вновь возобновились. За 1948 г. врачами института было обследовано 244426 человек, среди которых у 30945 человек была выявлена трахома, что составило $12,6 \%$ от общего количества осмотренных пациентов. Согласно данным сотрудников Башкирского трахоматозного института, своего пика эпидемия трахомы достигла в 1952 - 1953 гг., а последующие годы характеризовались постоянным снижением заболеваемости [23]. К 1956 г. произошло снижение уровня заболеваемости трахомой от 30 до $51 \%$ по 17 районам, от 10 до $30 \%$ - в 22 районах, до $10 \%$ - в 3 районах. В 6 районах заболеваемость оставалась на прежнем уровне, в 8 районах наблюдался рост заболеваемости.

За 1959-1961 гг. сотрудниками трахоматозного института было осуществлено 317 выездов в районы, проконсультировано 25716 человек, прооперировано 4545 пациентов [24, с. 9]. Были организованы 13 хирургических бригад, которые выезжали в районы с высокой заболеваемостью для проведения оперативной помощи на местах $[\mathbf{2 4}$, с. 6].

Таким образом, борьба с трахомой несколько десятилетий была приоритетной для всего коллектива Башкирского научно-исследовательского трахоматозного института и руководства республики в целом. Ценой самоотверженного и упорного труда медицинских и социальных работников, органов власти региона и самого населения к 1958 г. трахома как массовое заболевание была ликвидирована в 5 районах, к 1960 г. - в 40 районах, к 1962 г. - во всех районах Республики [5, с. 9]. Масштабы распространения заболевания и объемы профилактических и лечебных мероприятий со стороны государства были практически идентичны, что позволило побороть эпидемию. Различие в этом плане с частной благотворительной организацией было налицо: государство подключило все материальные и кадровые ресурсы для ликвидации трахомы.

Несмотря на полученные положительные результаты выездная работа не прекращалась и трахоматозный институт продолжал деятельность в данном направлении до полного устранения остаточных случаев заболевания. В период 1966-1971 гг. было осуществлено 432 выезда, осмотрено 358246 человек, проведено 20288 операций. В связи с ликвидацией трахомы Башкирский научно-исследовательский трахоматозный институт в 1965 г. был реорганизован в Уфимский научно-исследовательский институт глазных болезней Минздрава РСФСР.

С конца 1970-х гг. сотрудники института выезжали на долгосрочные командировки в Китай, Монголию, Турцию, Гвинею, Алжир для оказания квалифицированной офтальмологической помощи жителям этих стран. В начале 1990-х гг. Уфимский НИИ глазных болезней совместно с Детским фондом СССР проводил Всероссийскую акцию "Слепые дети", целью которой было обследование и оказание офральмохирургической помощи детям-учащимся школ-интернатов слепых и слабовидящих от Красноярского края до Дагестана. В 1990-2000-х гг. Уфимский НИИ глазных болезней оказывал офртальмологическую помощь жителям Курганской, Пермской, Челябинской и Свердловской областей. Офтальмологические бригады института выезжали в вышеперечисленные районы для оказания консультационной и хирургической помощи. Всего было проведено 23 выезда, во время которых осмотрено 9455 пациентов, из них более 200 получили хирургическую помощь на местах.

С 2006 г. Уфримский НИИ глазных болезней возобновил оказание регулярной выездной консультационной и офтальмохирургической помощи жителям районов республики Башкортостан. Необходимость в выездной помощи жителям районов возникла в связи с ликвидацией развернутых в 2000-х гг. микрохирургических центров, которые ранее на местах оказывали специализированную помощь. Особенно масштабными они стали начиная со второй 
половины 2017 г., когда было осуществлено 29 выездов, а осмотренные пациенты были приглашены на внеочередную хирургическую помощь в Уфимский НИИ глазных болезней. В 2018 г. уже было 294 выезда, во время которых консультационную помощь получили 13378 пациентов и 3203 - офтальмохирургическую на базе института. Начиная с 2019 г. офтальмохирургическая помощь начала производиться на базе самих лечебных учреждений республики, для чего операционная бригада института транспортировала в центральные районные больницы хирургическое оборудование и инструментарий. Это позволило оказать хирургическую помощь большему количеству населения - в 2019 г. было проведено 1524 операции. В 2020 г. было принято решение о возобновлении работы офртальмологических отделений на базе районных и городских больниц республики. Были введены в эксплуатацию офтальмологические отделения на базе центральных районных и городских больниц городов Мелеуз, Ишимбай, Сибай и Кумертау. По итогам 2020 г. на базе этих отделений операщионная бригада Уфимского НИИ глазных болезней провела 1085 операций [4, с. 6]. В январе 2021 г. был дан новый старт оказанию выездной помощи населению на территории Башкирии.

Таким образом, в научной работе проведен анализ работы выездных офртальмологических отрядов на территории Уфимской губернии и Башкирии начиная с конца XIX в. по сегодняшний день. Исследование показало, что имеется преемственность в оказании выездной офтальмологической, в том числе хирургической, помощи населению на примере деятельности окулистических "летучих" отрядов в конце XIX - начале XX вв., действовавших от имени Попечительства о слепых и противотрахоматозных отрядов в 20-60-х гг. XX в. под началом Минздрава страны и регионов. Отряды преследовали одну задачу - охват большего числа населения для предоставления им необходимой офтальмологической помощи, но различие в принадлежности к частной или государственной структуре сопровождалось трудностями на пути их деятельности. Если отсутствие финансовой поддержки, нехватка специалистов сопутствовали деятельности Попечительства о слепых, то государственная поддержка с возможностью предоставления полного пакета профилактических и лечебных мероприятий сопровождали работу противотрахоматозных отрядов под началом государственной системы здравоохранения, что позволило ликвидировать заболевание. На сегодняшний день, несмотря на возможности, предоставляемые каждому жителю страны на получение офртальмологической помощи, в отдаленных от центра населенных пунктах всегда есть и будут люди, особенно старшего возраста, которые зачастую не имеют возможности приехать в крупные офртальмологические клиники для получения хирургической помощи. В связи с этим оказание выездной офтальмологической помощи не теряет своей актуальности уже около 130 лет.

\section{Литература}

1. Акманов А.И., Галимова Ю.Ш. Организация выездного офтальмологического обслуживания населения Уфимской губернии в начале XX в. // Вестник Академии наук Республики Башкортостан. 2020. Т. 37. № 4 (100). С. 48-56.

2. Беллярминов Л.Г. Статистические данные о постоянной окулистической помощи в России. Материалы 8-го Пироговского съезда. СПб., 1902. Вып. 6. 17 с.

3. Бельский А.А. Обзор деятельности Уфимской глазной лечебницы Попечительства о слепых за 1 год. Киев, 1903.10 с.

4. Бикбов М.М. Анализ работы офтальмологической службы в республике Башкортостан по итогам 2020 г. Архив Уфимского НИИ глазных болезней. Уфа, 2020. 18 с.

5. Бикбов М.М. Ученые. Врачи. Учителя. Уфра, 2018. 48 с.

6. Бойко Э.В., Кириллов Ю.А., Рейтузов В.А. Л.Г. Беллярминов (к 155-летию со дня рождения) // Офтальмологические ведомости. 2014. T. VII. № 3. С. 93-101.

7. Борьба с трахомой. Охрана здоровья марийца // Красная Башкирия. 1926. № 14. C. 2 .

8. Головин С.С. О слепоте в России. Одесса, 1910. 124 с.

9. История офртальмологии в лицах, событиях, очерках /сост. Ярцева Н.С., Луцевич Е.Э. М., 2014. 424 с.

10. Клементьева Н.В. Здравоохранение Южного Урала: 1917-1936 гг. Дис. ... канд. ист. наук. Оренбург, 2013. 237 с. 
11. Князькина Т.А. Деятельность окулистического отряда Попечительства императрицы Марии Александровны о слепых в Камчатской области в 1912 г. // Вестник Омского университета. Серия: Исторические науки. 2018. № 2 (18). С. 80-85.

12. Кудояров Г.Х. Моя жизнь - офртальмология. Уфа, 2010. 172 с.

13. Нероев В.В., Захарова Е.К., Киселева О.А., Робустова О.В., Бессмертный А.М. Прошлое и настоящее мобильной офтальмологической помощи в России // Российский офтальмологический журнал. 2012. Т. 5. № 3. С. 107-111.

14. Отчет Особого отдела по предупреждению слепоты за 1899 г. /сост. Л.Г. Беллярминов, В.Н. Долганов, Л.П. Аствацатуров, М.И. Рейх. СПб., 1899. 180 с.

15. Отчет Особого отдела по предупреждению слепоты за 1901 г. / составлен под ред. проф. Л.Г. Беллярминова приват-доцентом В.Н. Долгановым. СПб., 1902. 142 с.

16. Рейтузов В.А., Мауленов Р.И. С.В. Очаповский: сообщение второе - становление врача // Научный вестник здравоохранения Кубани. 2017. № 4 (52). С. 57-67.

17. Семенченко И.В. Совершенствование земствами медицинского обслуживания населения на Урале в 1900-1918 гг. // Вестник Южно-Уральского государственного университета. Серия: Социально-гуманитарные науки. 2006. №17 (72). Вып. 7. С. 99100.

18. Соколова Е.И. Святая наука услышать друг друга. Ростов-на-Дону, 2005. 34 с.

19. Статистика слепых в России по переписи 1886 г. Разработан редакторами Центрального Статистического комитета В. Аленицыным и А. Сырневым. СПб.,1888. $223 \mathrm{c}$.

20. Танатарова М.С. Организация глазной помощи в Башкирской АССР за 40 лет // Сборник научных трудов Башкирского научно-исследовательского трахоматозного института. 1960. Т. 7. С. 6-9.

21. Трахома в горах // Красная Башкирия. 1926. № 255. С. 3

22. Ульянова Г.Н. Благотворительность и общественное призрение в России XIX - начала XX века. Институциональное развитие в контексте формирования гражданского общества // Труды Института российской истории РАН 1997-1998 гг. М., 2000. Вып. 2. С. 174-176.

23. Фиш М.М. Очерк деятельности Стерлитамакской земской глазной лечебницы и очерк распространения трахомы в Стерлитамакском уезде Уфимской губернии. Стерлитамак: Издание Стерлитамакского земства, 1904. 84 с.

24. Халитова C.X. Анализ мероприятий по ликвидации трахомы в Башкирской ACCP // Сборник научных трудов Башкирского научно-исследовательского трахоматозного института. 1963 . Т. 8. С. 4-9.

25. Хованский К.И. Трахома в Башкирии //Вопросы трахомы. 1934. Сб. 1. С. 9-13.

\section{Транслитерация по ГОСТ 7.79-2000 Система Б}

1. Akmanov A.I., Galimova YU.SH. Organizatsiya vyezdnogo oftal'mologicheskogo obsluzhivaniya naseleniya Ufimskoj gubernii v nachale XX v. // Vestnik Akademii nauk Respubliki Bashkortostan. 2020. T. 37. № 4 (100). S. 48-56.

2. Bellyarminov L.G. Statisticheskie dannye o postoyannoj okulisticheskoj pomoshhi v Rossii. Materialy 8-go Pirogovskogo s"ezda. SPb., 1902. Vyp. 6. $17 \mathrm{~s}$.

3. Bel'skij A.A. Obzor deyatel'nosti Ufimskoj glaznoj lechebnitsy Popechitel'stva o slepykh za 1 god. Kiev, 1903. $10 \mathrm{~s}$.

4. Bikbov M.M. Analiz raboty oftal'mologicheskoj sluzhby v respublike Bashkortostan po itogam $2020 \mathrm{~g}$. Arkhiv Ufimskogo NII glaznykh boleznej. Ufa, 2020. $18 \mathrm{~s}$.

5. Bikbov M.M. Uchenye. Vrachi. Uchitelya. Ufa, 2018. $48 \mathrm{~s}$.

6. Bojko EH.V., Kirillov YU.A., Rejtuzov V.A. L.G. Bellyarminov (k 155-letiyu so dnya rozhdeniya) // Oftal'mologicheskie vedomosti. 2014. T. VII. № 3. S. 93-101.

7. Bor'ba s trakhomoj. Okhrana zdorov'ya marijtsa // Krasnaya Bashkiriya. 1926. № 14 . S. 2 .

8. Golovin S.S. O slepote v Rossii. Odessa, 1910. $124 \mathrm{~s}$.

9. Istoriya oftal'mologii v litsakh, sobytiyakh, ocherkakh /cost. YArtseva N.S., Lutsevich E.EH. M., 2014. 424 s.

10. Klement'eva N.V. Zdravookhranenie YUzhnogo Urala: 1917-1936 gg. Dis. ... kand. ist. nauk. Orenburg, 2013. $237 \mathrm{~s}$.

11. Knyaz'kina T.A. Deyatel'nost' okulisticheskogo otryada Popechitel'stva imperatritsy Marii Aleksandrovny o slepykh v Kamchatskoj oblasti v 1912 g. // Vestnik Omskogo universiteta. Seriya: Istoricheskie nauki. 2018. № 2 (18). S. 80-85.

12. Kudoyarov G.KH. Moya zhizn' - oftal'mologiya. Ufa, 2010. $172 \mathrm{~s}$.

13. Neroev V.V., Zakharova E.K., Kiseleva O.A., Robustova O.V., Bessmertnyj A.M. Proshloe i nastoyashhee mobil'noj oftal'mologicheskoj pomoshhi v Rossii // Rossijskij oftal'mologicheskij zhurnal. 2012. T. 5. № 3. S. 107-111.

14. Otchet Osobogo otdela po preduprezhdeniyu slepoty za 1899 g. /cost. L.G. Bellyarminov, V.N. Dolganov, L.P. Astvatsaturov, M.I. Rejkh. SPb., 1899. 180 s. 
15. Otchet Osobogo otdela po preduprezhdeniyu slepoty za 1901 g. / costavlen pod red. prof. L.G. Bellyarminova privat-dotsentom V.N. Dolganovym. SPb., 1902. 142 s.

16. Rejtuzov V.A., Maulenov R.I. S.V. Ochapovskij: soobshhenie vtoroe - stanovlenie vracha // Nauchnyj vestnik zdravookhraneniya Kubani. 2017. № 4 (52). S. 57-67.

17. Semenchenko I.V. Sovershenstvovanie zemstvami meditsinskogo obsluzhivaniya naseleniya na Urale v 1900-1918 gg. // Vestnik YUzhno-Ural'skogo gosudarstvennogo universiteta. Seriya: Sotsial'no-gumanitarnye nauki. 2006. №17 (72). Vyp. 7. S. 99-100.

18. Sokolova E.I. Svyataya nauka uslyshat' drug druga. Rostov-na-Donu, 2005. 34 s.

19. Statistika slepykh v Rossii po perepisi $1886 \mathrm{~g}$. Razrabotan redaktorami TSentral'nogo Statisticheskogo komiteta V. Alenitsynym i A. Syrnevym. SPb.,1888. $223 \mathrm{~s}$.

20. Tanatarova M.S. Organizatsiya glaznoj pomoshhi v Bashkirskoj ASSR za 40 let // Sbornik nauchnykh trudov Bashkirskogo nauchno-issledovatel'skogo trakhomatoznogo instituta. 1960. T. 7. S. 6-9.

21. Trakhoma v gorakh // Krasnaya Bashkiriya. 1926. № 255. S. 3

22. Ul'yanova G.N. Blagotvoritel'nost' i obshhestvennoe prizrenie v Rossii XIX - nachala XX veka. Institutsional'noe razvitie v kontekste formirovaniya grazhdanskogo obshhestva // Trudy Instituta rossijskoj istorii RAN 1997-1998 gg. M., 2000. Vyp. 2. S. 174-176.

23. Fish M.M. Ocherk deyatel'nosti Sterlitamakskoj zemskoj glaznoj lechebnitsy i ocherk rasprostraneniya trakhomy v Sterlitamakskom uezde Ufimskoj gubernii. Sterlitamak: Izdanie Sterlitamakskogo zemstva, 1904. $84 \mathrm{~s}$.

24. KHalitova S.KH. Analiz meropriyatij po likvidatsii trakhomy v Bashkirskoj ASSR // Sbornik nauchnykh trudov Bashkirskogo nauchno-issledovatel'skogo trakhomatoznogo instituta. 1963. T. 8. S. 4-9.

25. KHovanskij K.I. Trakhoma v Bashkirii //Voprosy trakhomy. 1934. Sb. 1. S. 9-13.

Бикбов М. М., Галимова Ю. Ш. От окулистических "летучих" отрядов до офтальмологических бригад по обследованию населения.

Статья посвящена истории становления и развития окулистических "летучих" отрядов под началом Попечительства императрицы Марии Александровны о слепых, положивших начало оказанию выездной офртальмологической помощи населению страны, в частности на территории Уфимской губернии. В статье представлены причины возникновения "летучих" отрядов в конце XIX в., способы реализации поставленных перед выездными отрядами задач, их достижения и проблемы в деятельности. Авторы показывают преемственность развития оказания выездной офртальмологической помощи на примере работы окулистических "летучих" отрядов в Уфимской губернии, трахомных (трахоматозных) отрядов в Башкирской АССР в 20-60-е гг. XX в. и офтальмологических отрядов, действующих в настоящее время на территории Башкортостана.

Ключевые слова: попечительство о слепьх, окулистические "летучие" отряды, трахома, выездная ообтальмологическая помощь

Bikbov M. M., Galimova Yu. Sh. From ophthalmological flying squads to eye care teams for the examination of the populationa.

The article is devoted to the history of the formation and development of ophthalmological flying squads under the command of the guardianship of the Empress Maria Alexandrovna for the blind, which initiated the work of the mobile eye care teams to the population of the country, in particular on the territory of the Ufa province. The article presents the reasons for the emergence of "flying squads" at the end of the XIX century, the ways of implementing the tasks assigned to mobile teams, their achievements and problems in their activities. The authors show the continuity of the development of mobile eye care on the example of the work of ophthalmological flying squads in the Ufa province, trachoma (trachomatous) detachments in the Bashkir ASSR in the 20-60s. of the XX century and ophthalmic units currently operating on the territory of Bashkortostan.

Key words: guardianship about the blind, ophthalmological flying squads, trachoma, mobile eye care

Для цитирования: Бикбов М. М., Галимова Ю. Ш. От окулистических "летучих" отрядов до офтальмологических бригад по обследованию населения // Ойкумена. Регионоведческие исследования. 2021. № 3. C. 61-68. DOI: 10.24866/1998-6785/2021-3/61-68

For citation: Bikbov M. M., Galimova Yu. Sh. From ophthalmological flying squads to eye care teams for the examination of the population // Ojkumena. Regional researches. 2021. № 3. P. 61-68. DOI: 10.24866/1998-6785/2021-3/61-68 